\title{
THE INTERNATIONAL HUMANITARIAN RESPONSE TO THE REFUGEE CRISIS ALONG THE BALKAN ROUTE IN THE VIEW OF STRATEGIES OF INTERNATIONAL ORGANIZATIONS
}

\section{Veton Latifi}

South East European University, v.latifi@seeu.edu.mk

DOI: 10.1515/seeur-2017-0012

\section{Abstract}

Being one of the largest movements of displaced people through European borders since World War Two, the Syrian refugee crisis of 2015 and 2016, tested the coordination of the states and international organizations, and as well as the strategies for response of the latter to such enormous fluxes of displaced people along the Balkan corridor. The quick on-time reaction of the specialized humanitarian international organizations made significant achievements by the international organizations in terms of humanitarian assistance for the refugees and support for the governments of the region. Their approach mainly sought to create a partnership with the governments of the Balkan route in handling the serious humanitarian challenges (with a different strategy compared to other experiences, mainly this time through providing assistance and protection to the refugees throughout the corridor of the refugee crisis), it showed how important is such coordination at the end, with an aim to avoid further human catastrophes along refugee routes, and to avoid major security repercussions for the countries of the region.

With a comparative approach, the paper analyzes the response of the 
international organizations in terms of the strategies they have applied along the Balkan human corridor and their new innovative approaches used in terms of the coordination with the local authorities and governments of the Balkan route. Different to previous forms of humanitarian interventions and dynamics of the refugee crisis (dissolution of Yugoslavia in 1990s), the roles of the international organizations along the Balkan human corridor following the Syrian war of 2015 and 2016 have shaped many innovative dimensions, including firstly their advising orientation and support for refugees and local authorities (mainly through providing help on legal issues). Apart from humanitarian activities for delivering direct aid, the major intergovernmental organizations (most of them operating under the umbrella of the UN) following the implementation of border controls from very beginning of the refugee crisis have been focused in supporting the local authorities as well as on regulating the flow of migrants. The strategies of response by the international organizations in the latest case of the Balkan human corridor notably shifted from the classical humanitarian dimension of their reactions. These strategies have played as well an important role in advising, and especially in developing a partnership with the local authorities capacity building and legal support for both local institutions and refugees. However, through the comparative approaches the paper identifies that there are different models of management roles played by the specialized international organizations in various countries of the Balkan route and its frontiers.

Key words: international organizations, refugee crisis, Balkan refugee route, UN agencies, strategies.

\section{Introduction}

As humanitarian needs of the refugees along the Balkan refugee route became increasingly severe during 2015 and first part of 2016, the major specialized international organizations have been involved in direct help of the refugees and migrants, and in helping the governments of the region to cope with the crisis through various coordinative and supportive actions.

Apart from humanitarian activities for delivering direct aids, the major intergovernmental organizations (most of them operating under the umbrella of the UN) following the implementation of border controls from the very beginning of the refugee crisis, have been focused in supporting the local authorities in regulating the flow of migrants as large numbers of people in several periods of the 2015 and 2016 have been waiting at borders of Balkan 
states, often for many days, while others have been refused entry altogether and face limited options for either onward movement or return. With their limited resources rapidly depleted during delays, large numbers of migrants in the last few months became increasingly reliant on humanitarian assistance and advice to be provided by international organizations either in a direct way or indirectly through the help or advice of the local organizations and institutions.

\section{Comparative Analysis of The Response And Strategies Of The International Humanitarian Organizations}

A flow of refugees and migrants following the conflicts and refugee crises in several Asian and African countries required the involvement of the specialized international organizations (IO) among others along the Balkan refugee route as well, while the highest level of forcibly displaced people worldwide since World War II moved to northern European countries.

A panel discussion at South East European University in Tetovo (organized for the methodological purposes of this paper within the annual conference on May $17^{\text {th }} 2016$ with the country representative of the UNHCR, IOM, and other international and local organizations working on the field and university professors) identified several common positive key roles and responses conducted by the international organizations up to date during the refugee crisis along the Balkan human corridor. All of the roles seems to be of supportive nature for the local authorities (the governments of the region) and for the transit of the refugees along the route. Their efficient role in monitoring the asylum system in cooperation with the governments was recognized (Latifi, 2016: 159-160), as well as the help provided in sustainable coordinative actions with all actors involved in dealing with the refugee crisis and work with the partners.

The role of the international organizations within the refugee crisis of 2015 and 2016 along the Balkan route goes beyond their role during the Kosovo crisis of 1999 that anyway had another nature as well. However, the international organizations in the latest case in the Balkans moved ahead from the classical humanitarian dimension of their reactions and apart from providing an immediate support of the people who need help during the refugee crisis, they have played as well as an important role in preventing nature, advising, and especially in terms of developing a partnership with the local authorities in border management, capacity building and legal support for both local institutions and refugees. 
The overall role of the international organizations should be estimated as well as within their expressed flexibility to work with the people and governments of the region, and as well within their extraordinary readiness and will for quick reactions in supporting the state institutions in handling the refugee fluxes. During the Syrian refugee crisis, at least along the Balkan route, the response of the international organizations proved to be a motivating factor for an effective support and coordination that the countries of the region (non-EU members) received financial support directly from the international organizations. Additionally, a careful approach of the profiled international organizations in avoiding any potential frustration of the countries of the region (especially about the sovereignty concerns that sometimes became visible in Macedonia and in Greece to some extent as well), helped a lot in creating a positive clime of the relationship among the international organizations and local authorities, in most of the time of the refugee crisis. The involvement of the specialized refugee IOs in the countries of the region was conducted under well-structured motives and planned strategies in most of the cases: a quick intervention of the international organizations for the sake of giving enough time to the state institutions to organize their capacity for handling the refugee fluxes and situations. This time in fact the countries of the region were much better organized compared to the Kosovo crisis and they responded as a result of the quick reaction of the specialized international organizations, especially following on time reactions of the IOM, UNHCR, UNICEF, etc.

Within this scope, the following functions of the international organizations have been exercised along the Balkan human corridor in most of the countries that served as a transit:

- Supply of food and non-food items, wash supply, etc.;

- Legal instructions of the refugees (referral to legal support)- in case they apply for asylum instructed of their rights, AVR (assisted voluntary return)- latest initiative in early phase;

- Capacity building for the state institutions with a priority for ministries of interior (border sector), ministries of labor and social issues, national centers of crisis management- all that via providing training, donating equipment, providing and donating computers for better communications, filtering stations, etc.;

- Support for community projects of the type of medical centers and repairing hospitals for quick reactions in small towns along the border passages, etc.

However, there are different models of management roles played by the specialized international organizations in various countries of the Balkan route and its frontiers. For instance, in Turkey the management of the refugee 
camps is related to the government and in a different way in Macedonia the international organizations are involved in managing the camps with food supplies, clothes, containers, etc. In Turkey the international organizations are not involved so much in supporting the issues related to the camps, but rather the support have another approach and nature. In countries like Macedonia and Serbia the international organizations are involved in infrastructure support, organizing and equipping the camps through IOM, UNHCR, UNHCR and other donors. By contrast, in Turkey even the international humanitarian organizations have not a lot of the access in managing activities of the refugee crisis. In Greece, the international organizations play mainly a supportive role to the institutions, but different to the other Balkan countries, in Greece the financial aid of the EU programs for support of the refugee crisis (Cherubini, 2015: 240-241) goes into the Greek government which then distributes these finances across the international organizations. That is contrary in the case of Macedonia and Serbia when the EU for instance first donated financial aid to the international organizations and then to the partners.

Different to the Greek experience that even before the international organizations' involvement in the country was at least using some more sustainable and realistic methodology of work based on the prior experiences with the refugees along the border with Turkey, and based on direct information access and coordination with the EU member states, the behavior of the Macedonian Center for Crisis Management and other authorities was based on data, information and analysis of representatives of the International Red Cross, IOM, police and UNHCR transmitted to the representatives of the Center during their daily communication on the ground, without any structured methodology of monitoring the situation. Since the involvement of the specialized humanitarian international organizations, the authorities of both countries (Greece and Macedonia) and especially the Macedonian ones benefited significantly from the help of advice and access to equipment and databases of the specialized international organizations for improving their methodology of daily work.

Prior to the involvement of the international organizations, local capacities were quite limited, not coordinated and not well enough organized when the refugee crisis escalated along the Balkan route. For instance, at the beginning the Macedonian Center for Crisis Management was missing a clear strategy and any idea initially how to respond to the new ongoing refugee crisis. A similar situation was in Greece: the Greek Government found itself in a difficult situation as well being at the same time occupied additionally with the financial problems. In both countries the local capacities were almost 
incompetent to deal with this new kind of refugee flux in such a massive way. Furthermore, both countries initially possessed only limited professional capacities and with no clear concepts how to react to the flux of refugees. This lasted until the advising role of the specialized international organizations started to prepare the local Greek and Macedonian authorities to avoid any improper reaction to the refugees that would eventually be in disproportion to the humanitarian aspect, and to advise them by sharing the best models for their treatment as transitive fluxes.

\section{Approaches Of The International Organizations}

From countries to countries along the Balkan human corridor the approaches of the international organizations used for handling the refugee crisis seem to be varying and often different strategies. There were variations in the coordination with the national governments in border control management and in assisting the local authorities to cope with the enormous refugee crisis. It is a notable part of the strategy that the international organizations undertook no major initiatives without joint efforts and coordination with the national governments and local institutions. The international organizations applied an approach that was mainly oriented to assist to the state institutions as partners in managing the situation along the Balkan route.

Often, along the Balkan human corridor, if there had not been the involvement of the international organizations with specific and on-time approaches in urging the governments of the region, leaving initiatives on their own to the authorities, the latter would use either the state's belated attempt to make its role and presence noticeable in the humanitarian response, or their engagement was primarily guided by national security interests. For instance in Greece only on January 28, 2016, a joint Ministerial Decision banned all independent, unregistered volunteer activities conducted on the islands, and placed NGOs and other civil society actors under state monitoring at organizational and individual levels (Statewatch, 2016). And the role of the international organizations, with a well-planned strategy was approached in a different way and in different phases to particular countries. For instance, in the Macedonian part of the Balkan route, the international organizations (led mainly by those specialized UN agencies of the field) identified the best models and ways for the local authorities in the form of assisting them for the start, or react in the initial phase of the major refugee fluxes until the state institutions organize themselves for a response in handling the refugee fluxes, and then continue to behave in the advising capacity for the local authorities, 
while being careful not to cause any kind of frustration among political elites of the country undergoing the serious internal inter-party political crisis. In contrast, in Turkey, even the international organizations were not used to have a lot of access to the handling of the refugee crisis.

The approaches were different even in financial aid models. For instance in Greece, the international organizations worked in a supportive capacity only to the Greek government in handling the refugee crisis, while the EU's financial aid programs for support are delivered to the Greek government and then the latter redistribute them to the international organizations offices.

\section{The Roles Of The Intergovernmental Organizations In Terms Of The Humanitarian Strategies And Coordination}

The main roles of the international organizations along the Balkan human corridor in dealing with the refugee crisis have been shaped by their main priorities that are met in an effective way: to assist the governments and civil society in responding to the most urgent humanitarian and protection needs of the refugees; and to strengthen the asylum systems in the countries in line with applicable international standards.

In general, the international humanitarian organizations provided assistance with legal services to the Balkan countries, but a special emphasis was paid to the case of Macedonia, having in mind the previous experiences with this country in the initial phase of the Kosovo refugee crisis of 1999 on one side, and as well because of the ongoing domestic political circumstances that may result in furious reaction toward the refugee fluxes by political actors for the aims within their highly polarized internal rivalries with the blocked EU integration blocked process. (Ilievski and Serbos, 2016: 53) To this extent, Greek authorities already met some previous experiences with the refugees from Asia and Africa in much earlier phases compared to Macedonia, because of the sea routes of Greece that were used earlier by the refugees.

The roles of the international organizations along the Balkan human corridor have many innovative dimensions. First of all, their advising orientation and support for refugees and local authorities, mainly provided help on legal issues. Following the advocacy of the international organizations and civil society, crucial amendments to the asylum legislation in Macedonia (for instance) were adopted in June 2015, allowing refugees 72 hours to transit through the country unhindered. Many refugees and migrants whose access was blocked turned to smuggling networks and there has been a rise in reports of abuse 
by smugglers and gangs. The major international organizations (mainly UNHCR and IOM) have responded in quite innovative and appropriate ways in preventive efforts against smuggling. Again, the support and coordination with the local authorities in this view has been crucial.

The Regional Refugee and Migrant Response Plan that presents a framework for an inter-agency response to the refugee and migrant mass flows into Europe through the Eastern Mediterranean and Western Balkans route, sets out the overall general roles of the international organizations:

- To design and implement a response that supports, complements and builds Governments' existing capacity to ensure effective and safe access to asylum, protection and solutions in relevant countries, as well as manage migration in an orderly and dignified manner while protecting the human rights of all refugees and migrants.

- To ensure that refugees and migrants have access to protection and assistance in a participatory manner, with particular attention to specific needs.

- To strengthen national and local capacities and protection systems and ensure safe access to longer-term solutions for refugees and migrants who may become stranded, may want to apply for asylum, or may want to return voluntarily to their countries of origin.

- To strengthen partnership and coordination within the humanitarian community and with governments, both in setting common goals and in establishing national-level coordination structures and information analysis, that ensure an efficient and coordinated response, including coordinated channels for citizen engagement to support the reception and integration of refugees and migrants. (RRMMP, 2016)

\section{The Response Of Particular Specialized International Organizations}

In the period of 27 March- 05 April 2016 an Information and Communication needs assessment was conducted in Tabanovce transit center in the northern part of Macedonia, nearby the border with Serbia with an order to identify the information and communication needs of refugees and migrants, as well as the most appropriate channels for information sharing. The results of the assessment indicate that $80 \%$ of respondents said that UN agencies and other international organizations were the most reliable source of information - UNHCR, IOM , Red Cross, etc. (Information and Communication Needs Assessment, 2016, p. 3)

In line with the Refugee Coordination Model the UNHCR continued to closely support the governments of the region in its primary protection responsibility, advising capacity and coordination. Much of the humanitarian relief in these countries of the region is coordinated and channeled through the UNHCR (United Nations Higher Commission for Refugees). It assists the Government 
and civil society in responding to the most urgent humanitarian and protection needs of the refugees; and as well as strengthen the asylum systems in the country in line with applicable international standards (Inter-Agency Operational Update, 2016, p.1.) The priorities and roles of the UNHCR are fitting in the region especially when it comes to its boost reception capacity and providing emergency assistance in receiving countries through support of states, civil society and local communities.

The International Organization for Migration (the IOM) has been acting all the time with its partners in the international community to assist in meeting the growing operational challenges of migration management; advance understanding of migration issues; encourage social and economic development through migration; and uphold the human dignity and wellbeing of migrants.

The UNICEF (United Nation's Children Fund) has responded to the crisis through a combination of advocacy, technical assistance to the Government, capacity building and service delivery response, and it is working to extend support to children and women throughout their journey in Greece, Austria and Italy. It is actively engaged in regular Government and UN country team coordination mechanisms on the refugee and migrant crisis. (Regional Humanitarian Situation Report, No. 8, p. 2)

In general, the main elements of the protection response of these particular specialized humanitarian organizations (UNHCR, IOM and UNICEF) have been conducted on the ground along the Balkan route in 2015 and 2016 in a successful way and they include:

- Protection monitoring and advocacy

- Strengthening national asylum systems

- People with specific needs

- Child protection

- Family reunification and prevention of family separation

- Prevention and response to sexual and gender-based violence (RRMMP, 2016).

Apart from these international organizations, other partners working with the Ministries and municipalities in providing protection and assistance to refugees among others includes as following: Caritas, Danish Caritas, DRC, GIZ, Grain of Goodness, Habitat for Humanity, Mercy Corps, Red Cross, SOS Children's Village, Télécoms Sans Frontières (TSF), UNFPA, and WHO (Inter-Agency Operational Update, 2016, p.18) 


\section{The Balkan Human Corridor Following The Response Of The International Humanitarian Organizations}

Being one of the largest movements of displaced people through European borders since World War Two, the refugee crisis brought in a test of the coordination of states and international organizations. The international community was caught unprepared for such large numbers of people. (RRMMP, 2016) While the overall response of several states has remained unstructured, on another hand the quick and on time reaction of the specialized international organizations have made significant achievements. The international organizations involved in terms of humanitarian assistance for the refugees and support for the governments of the region led this effort.

The Balkans corridor has been officially closed since the EU-Turkey Plan was first announced on 8 March 2016. This has resulted in the emergence of new smuggling routes, through the Balkans. For those currently stranded in Serbia and Macedonia, needs have begun to shift from access to shortterm lodging, food and non-food items such as shoes and jackets, to longerterm shelter, adequate hygiene facilities (toilets and bathing facilities) and healthcare. When asked how their needs might change if they were to remain in the same location for longer than two weeks, migrants reported medical care and proper sanitation and bathing facilities among their top priorities. So, conditions will need to be improved in order to avoid further outbreaks of disease and to maintain adequate and dignified conditions for the thousands who remain stranded in the sites across the Balkans. (European Migration Crisis Rapid Situation Update, 2016, pp. 5-6) The international organizations UNHCR, IOM, UNICEF and the others should continue to play an important role if they remain committed to continue to maintain staff presence and operational capacity not only in Syria and neighboring states, but as well as alongside including the Balkan countries with close coordination of activities with UN, host governments and partner agencies.

It will be very important for the entire process related to the refuge crisis along the Balkan human corridor for these international organizations led by the UNHCR to strengthen protection systems and prevent refoulement including through presence and capacity building and, at the same time, increase strategic messaging and advocacy to and about persons of concern. (ERER Update, No. 24, 2016) And to address the deteriorating eventual regional situation, IOM's engagement along the Balkan human corridor should further be prioritizing: provision of emergency shelter materials, distribution of nonfood items (NFIs), needs assessments/ needs analysis, emergency healthcare 
and referrals, transport assistance for refugees; resettlement assistance for refugees; repatriation of stranded and vulnerable migrants; and livelihood support.

\section{Partnerships With The National And Local Authorities}

The specialized international organizations during the refugee crisis along the Balkan human corridor were oriented all the time in playing a specific role of partners of local institutions first and then to react with their direct humanitarian programs and capacities. And those cases of on-time reactions of the governments of the region in handling the refugee crisis came as a result mainly of the quick partnership approach of the IOs in the early phases, including the quick constructions of the refugee camps (for instance), that showed to be a significant advantage for the local authorities.

In fact, it proved along the Balkan human corridor the issue of the partnership and coordination of the international organizations with all relevant actors in the process was not problematic. For instance the UN organizations led by the UNHCR in line with their refugee mandate they have been coordinated with the governments on the overall refugee response and they continue their leadership with the Refugee Coordination Model and closely have been supported the governments in their primary protection responsibility. For instance, the UNHCR in Skopje has established regular coordination meetings that are now co-chaired with the Ministry of Labor and Social Policy, including bi-weekly coordination meetings for food and non-food (NFIs) assistance to identify needs and remaining gaps and ensure complementarity of response from all partners involved in the crisis. (Latifi, 2016: 167)

Following the new applied strategy of the international organizations in handling the refugee crisis along the Balkan route, it is obvious that the profiled humanitarian intergovernmental organizations as partners to the state institutions of the countries of the region can be of great help in preventing the human catastrophe along human corridors via quick and coordinated response of both sides. As a result, the construction of the refugee camps along the Balkan route was conducted in a much more effective way compared to the other regions and compared to the previous Balkan refugee crisis indeed. Or, for instance the early warning system of the IOM (supported financially by the Swiss Agency for migration) government helped the governments of the region to work in coordinated way with the international organizations in real monitoring of the Balkan route, as well as exchange information among all the countries of the region. 
Such coordinated actions showed to be of great help for the state institutions to respond on time to the major refugee fluxes, to help the centers and ministries in real time to prepare food for appropriate numbers of refugees, to prepare their shelter, etc. Or, in the case of innovative use of the technologies for realtime update and data exchanges data among various countries for several parts of the routes which was part of the strategy of the international organizations how to cooperate in partnership way with the local partners during the 2015 and 2016 refugee crisis (like the IOM project DTM (Data Trace Matrix) for quick update through tablets for many countries worldwide including the Balkan route). Such kinds of innovative approaches in enhancing the cooperation of the international organizations with the national and local authorities to the dimension of partnership is a new part of the applied and already tested strategies of the international organizations for a better coordination with the local partners. In fact, these actions by the international organizations oriented toward developing long-term partnerships with the local state institutions (of the countries of the refugee route) is notable part of a successful humanitarian strategy in working together to respond on time properly and to avoid in preventive way the worst scenarios for everyone in the field.

\section{Conclusion}

The Syrian refugee crisis is one of the largest movements of displaced people through European borders since World War Two, and it brought in a test of the coordination of the states and international organizations. While the overall response of several states of the Balkan human corridor has remained unstructured, the quick and on time reaction of the specialized international organizations have made significant achievements, particularly by the international organizations involved in terms of humanitarian assistance for the refugees and support for the governments of the region. The refugee crisis of 2015-2016 along the Balkan humanitarian corridor has included an innovative role of the international organizations compared to the previous refugee crisis along human corridors mainly focused only on the scope of the assistance and coordination. In both cases, the role of the intergovernmental organizations in terms of the humanitarian strategies and coordination has been conducted via quick responses and advising aims. The international humanitarian organizations (led by the UNHCR and IOM) have been the main partners supporting the governments of the Balkans in handling the serious humanitarian challenges through providing assistance and protection to the refugees throughout the refugee crisis. The continuous support for the governments of the Balkans human corridor remained to be present as well 
as for a longer period even after the major fluxes of refugees from Syria, Pakistan, Afghanistan, Iraq and other countries were minimized, with their assistance keeping focus on the strengthening of the asylum system in these countries, monitoring access to the territory, and improving services and facilities for persons staying in the country for the foreseeable future, which again showed once more the innovative approach of the strategies of response of the international humanitarian organizations in handling the refugee crisis along the Balkan route especially.

\section{References}

- Cherubini, F., Asylum Law in the European Union, Routlege, New York, 2015.

- European Migration Crisis Rapid Situation Update, REACH, April 05, 2016.

- Europe's Refugee Emergency Response (ERER) Update, No, 24, Skopje, 19-25 February 2016.

- FYR Macedonia, Inter-Agency Operational Update, UNHCR, Skopje, 4 31 March 2016.

- Ilievski, Z. and Serbos, S., "EU perceptions of the crisis and their impact on relations between Greece, Macedonia and other Balkan states", in Philips, David (ed.), Balkan Human Corridor, Institute for the Study of Human Rights at Columbia University, New York, 2016, pp.53-66.

- Information and Communication Needs Assessment, UNHCR, Skopje, April 2016.

- Latifi, V., "The international organizations role in handling the refugee crisis along the Balkan human corridor" in Philips, David (ed.), Balkan Human Corridor, Institute for the Study of Human Rights at Columbia University, New York, 2016, pp.158-170.

- Refugee and Migrant Crisis in Europe, Regional Humanitarian Situation Report, No. 8, UNICEF, Skopje, February, $16^{\text {th }}, 2016$.

- Regional Humanitarian Situation Report, No. 8, UNICEF, 2016.

- RRMMP, Regional Refugee and Migrant Response Plan for Europe: Eastern Mediterranean and Western Balkans Route, UN, January - December 2016.

- Statewatch, NGOs and volunteers helping refugees in Greece to be placed under state control, February 21, 2016. Available at: http://www.statewatch. org/news/2016/feb/eu-med-crisis-volunteers-state.htm, last time accessed on November 03, 2016. 